\title{
Carbon monoxide effects on human ventricle action potential assessed by mathematical simulations
}

\author{
Beatriz Trenor ${ }^{1}$, Karen Cardona ${ }^{1}$, Javier Saiz ${ }^{1}$, Sridharan Rajamani ${ }^{2}$, Luiz Belardinelli ${ }^{2}$ and \\ Wayne R. Giles ${ }^{3 *}$ \\ 1 Instituto Interuniversitario de Investigación en Bioingeniería y Tecnología Orientada al Ser Humano, Universitat Politècnica de València, Valencia, Spain \\ 2 Cardiovascular Therapeutic Area, Gilead Sciences, Foster City, CA, USA \\ ${ }^{3}$ Faculty of Kinesiology, University of Calgary, Calgary, AB, Canada
}

Edited by:

Christopher Huang, University of

Cambridge, UK

Reviewed by:

Gareth D. K. Matthews, University of Cambridge, UK

Christopher Huang, University of

Cambridge, UK

*Correspondence:

Wayne R. Giles, Faculty of

Kinesiology, University of Calgary,

2500 University Drive, Calgary $A B$

T2N 1N4, Canada

e-mail:wgiles@ucalgary.ca
Carbon monoxide (CO) that is produced in a number of different mammalian tissues is now known to have significant effects on the cardiovascular system. These include: (i) vasodilation, (ii) changes in heart rate and strength of contractions, and (iii) modulation of autonomic nervous system input to both the primary pacemaker and the working myocardium. Excessive $\mathrm{CO}$ in the environment is toxic and can initiate or mediate life threatening cardiac rhythm disturbances. Recent reports link these ventricular arrhythmias to an increase in the slowly inactivating, or "late" component of the $\mathrm{Na}^{+}$current in the mammalian heart. The main goal of this paper is to explore the basis of this pro-arrhythmic capability of $\mathrm{CO}$ by incorporating changes in $\mathrm{CO}$-induced ion channel activity with intracellular signaling pathways in the mammalian heart. To do this, a quite well-documented mathematical model of the action potential and intracellular calcium transient in the human ventricular myocyte has been employed. In silico iterations based on this model provide a useful first step in illustrating the cellular electrophysiological consequences of $\mathrm{CO}$ that have been reported from mammalian heart experiments. Specifically, when the Grandi et al. model of the human ventricular action potential is utilized, and after the $\mathrm{Na}^{+}$and $\mathrm{Ca}^{2+}$ currents in a single myocyte are modified based on the experimental literature, early after-depolarization (EAD) rhythm disturbances appear, and important elements of the underlying causes of these EADs are revealed/illustrated. Our modified mathematical model of the human ventricular action potential also provides a convenient digital platform for designing future experimental work and relating these changes in cellular cardiac electrophysiology to emerging clinical and epidemiological data on $\mathrm{CO}$ toxicity.

Keywords: carbon monoxide (CO), late sodium current $\left(I_{\mathrm{Na}-\mathrm{L}}\right)$, action potential (AP), early after-depolarizations (EADs), S-nitrosylation

\section{INTRODUCTION}

It is now well known that carbon monoxide (CO) has significant physiological and pathophysiological effects in a number of different organ systems in mammals (Wu and Wang, 2005). This paper considers $\mathrm{CO}$ induced ventricular rhythm disturbances in the human heart. Recently, attention has been drawn to the fact that $\mathrm{CO}$ can induce cardiac arrhythmias. This is based on a number of studies in animal models and literature regarding emergency hospital admissions due to life-threatening cardiac rhythm disturbances triggered by increases in ambient levels of CO (Goldstein, 2008; Bell et al., 2009; Dallas et al., 2012). More generally, substances somewhat similar to $\mathrm{CO}$, including nitric oxide $(\mathrm{NO})$, and hydrogen sulfide $\left(\mathrm{H}_{2} \mathrm{~S}\right)$ are now often referred to in the neurophysiological literature as gaseous transmitters (Leffler et al., 2006). These compounds are receiving increased attention as (i) mediators or modulators of significant, sometimes acute pathophysiological challenges, and as (ii) potential targets for therapeutic interventions (Motterlini and Otterbein, 2010).
The ability of CO to alter electrophysiological activity in the heart and nervous system has led to quite broad-ranging examinations of the ability of $\mathrm{CO}$ to regulate specific ion channels (Wilkinson and Kemp, 2011). These effects can occur either as direct actions of CO, or (and more commonly) CO effects on closely related intracellular signaling pathways, often involving nitric oxide signaling, metabolism, and/or downstream targets for chemical modifications of individual amino acids in functional proteins. In the cardiovascular system, specific attention has been drawn to S-nitrosylation of, specific ion channel residues (Jaffrey et al., 2001; Haldar and Stamler, 2013).

In this paper, our focus will be on the cellular electrophysiological effects of $\mathrm{NO}$ and related S-nitrosylation of specific sites on ion channels, ion transporters, or directly related signaling molecules (Jaffrey et al., 2001; Tamargo et al., 2010; Haldar and Stamler, 2013). This is because many cellular effects initiated by increased $\mathrm{CO}$ levels are mediated by downstream changes in $\mathrm{NO}$ and ultimately through targeted nitrosylation of defined sites (residues). At present, it is known that NO/S-nitrosylation can: 
(i) increase the background $\mathrm{K}^{+}$current that generates the resting potential in heart (Gómez et al., 2009) (ii) activate ATP sensitive $\mathrm{K}^{+}$channels in neurons (Kawano et al., 2009), and (iii) reduce a major repolarizing current $\left(\mathrm{K}_{\mathrm{v}} 1.5\right)$ in mammalian atria (Núñez et al., 2006). In addition, a similar CO and/or NO induced reaction mechanism, as S-nitrosylation, can modulate (iv) $\mathrm{Na}^{+} / \mathrm{K}^{+}$ ATPase turn over in the hypoxic heart (Yakushev et al., 2012), and (v) alter release of $\mathrm{Ca}^{2+}$ from the sarcoplasmic reticulum (SR) by targeting the ryanodine receptor complex in heart and skeletal membranes (Gonzalez et al., 2010; Wang et al., 2010). There is also evidence that $\mathrm{NO}$ can increase the slowly inactivating or late $\mathrm{Na}^{+}$current in nerve, muscle and heart preparations (Ahern et al., 2000; Evans and Bielefeldt, 2000).

Two recent papers (Abramochkin et al., 2011; Dallas et al., 2012) have reported CO induced changes in electrical activity and contractions, as well as induction of cardiac arrhythmias in a rat ventricle model. Evidence that a major ion channel mediated effect is an augmentation of slow inactivation of the cardiac $\mathrm{Na}^{+}$current is provided. These results also emphasize an essential involvement of $\mathrm{NO}$ as a second messenger of this COinduced effect. CO-induced increases in this late $\mathrm{Na}^{+}$current, $\mathrm{I}_{\mathrm{Na}-\mathrm{L}}$, can significantly lengthen the action potential (AP) and result in abnormal electrical activity (early after-depolarization, EADs) characterized by repetitive firing, even after application of only one stimulus (Dallas et al., 2012). This arrhythmia can be reduced substantially following superfusion of this experimental preparation with the compound ranolazine (Dallas et al., 2012). Ranolazine, originally developed as a coronary vasodilator, is now known to be a potent and quite selective inhibitor of the $\mathrm{I}_{\mathrm{Na}-\mathrm{L}}$ in a number of different mammalian preparations (Makielski and Valdivia, 2006; Zaza et al., 2008), and also in human ventricle (Moss et al., 2008). Ranolazine effects are significant in the settings of stable angina and also in heart failure where, in both cases, it is known that $\mathrm{I}_{\mathrm{Na}-\mathrm{L}}$ is increased (c.f. Trenor et al., 2012).

The main goal of our mathematical simulations is to illustrate, using a current mathematical model of the AP in human ventricle, the consequences of a CO induced: (i) increase in $\mathrm{I}_{\mathrm{Na}-\mathrm{L}}$, (ii) NO-S-nitrosylation induced changes in $\mathrm{I}_{\mathrm{Ca}-\mathrm{L}}$, and (iii) this combination. For this purpose, CO-induced changes in $\mathrm{I}_{\mathrm{Na}-\mathrm{L}}$ that are similar to those reported in the primary experimental data (Dallas et al., 2012) were introduced into two different models of the ventricular AP and the consequences were explored systematically.

\section{METHODS \\ HUMAN VENTRICULAR MYOCYTE MODELS}

To simulate the electrical activity of human ventricular myocytes, two relatively recent AP models were evaluated. The Grandi et al. model (Grandi et al., 2010) is perhaps the most detailed mathematical model that is available, when judged in terms of its comprehensive ionic current portfolio and inclusion of mathematical expressions for the $\mathrm{Ca}^{2+}$ transient and $\mathrm{Ca}^{2+}$ homeostasis in the human ventricle. For the purpose of simulating some aspects of heart failure we have previously modified and utilized the original Grandi et al. model (Trenor et al., 2012). In this paper, the slowly inactivating component of $\mathrm{I}_{\mathrm{Na}}$, which is denoted $\mathrm{I}_{\mathrm{Na}-\mathrm{L}}$, was reformulated based on experimental data. In the simulations presented here, we have made use of this code: specifically the
Grandi model was employed after (i) modifying the $\mathrm{Na}^{+}$current as in (Trenor et al., 2012), (ii) changing the L-type $\mathrm{Ca}^{2+}$ current, $\mathrm{I}_{\mathrm{Ca}-\mathrm{L}}$, or (iii) both.

Early in this study, some simulations were carried out using the latest human ventricular AP model published by O'Hara et al. (2011). This model is based on experimental data taken from 140 healthy human hearts; it encompasses the formulation of 18 ionic currents and carrier-mediated fluxes and a detailed formulation of steady-state and transient ion concentrations, including intracellular $\mathrm{Ca}^{2+}$ transients. This model reproduces many aspects of the electrophysiological behavior of human ventricular myocytes with high fidelity, and can simulate some AP alterations due to drug effects. However, it appears not to be able to generate/exhibit any EADs in response to the reported, $\mathrm{CO}$ induced, changes in $\mathrm{I}_{\mathrm{Na}}$ or $\mathrm{I}_{\mathrm{Ca}}$ or their combination. We have not explored the reasons for this in detail; however, it is likely that the net current at the level of the plateau of the AP is an area for further examination/modification.

\section{SIMULATION OF CO EFFECTS}

As reported in (Dallas et al., 2012), CO can reduce peak transient inward $\mathrm{I}_{\mathrm{Na}}$ by as much as $50 \%$, shift the inactivation curve in hyperpolarizing direction, and significantly increase the late sodium current $\mathrm{I}_{\mathrm{Na}-\mathrm{L}}$. Thus, in our simulation $\mathrm{CO}$ effects on the fast component of $\mathrm{I}_{\mathrm{Na}}$ were modeled by introducing a $50 \%$ decrease in $\mathrm{I}_{\mathrm{Na}}$ maximum conductance and a $5 \mathrm{mV}$ shift in the hyperpolarizing direction of the two $\mathrm{Na}^{+}$current inactivation relationships $h_{\infty}$ and $j_{\infty}$ (see Equation 1 ). In addition, $\mathrm{I}_{\mathrm{Na}-\mathrm{L}}$ was increased 2-fold compared to its values in the original Grandi et al. model (Trenor et al., 2012).

$$
h_{\infty \_ \text {shifted }}=j_{\infty \_ \text {shifted }}=\frac{1}{\left(1+e^{\frac{V_{m}+71.55+5}{7.43}}\right)^{2}}
$$

$V_{m}$ is the membrane potential.

CO is known to elevate NO levels (Dallas et al., 2012), and this "second messenger" can have important effects on L-type $\mathrm{Ca}^{2+}$ current, $\mathrm{I}_{\mathrm{Ca}-\mathrm{L}}$, in the mammalian (ferret) heart, as documented in the detailed studies of Campbell et al. (1996). These investigators reported a significant increase in $\mathrm{I}_{\mathrm{Ca}-\mathrm{L}}(30-50 \%)$ under conditions of NO induced S-nitrosylation of this $\mathrm{Ca}^{2+}$ channel $\alpha$-subunit. In addition, this paper also reported a nitrosylation induced change in $\mathrm{I}_{\mathrm{Ca}-\mathrm{L}}$ gating-specifically a small but significant change in the voltage dependent activation relationship-an approximately $6.5 \mathrm{mV}$ shift in the hyperpolarizing direction. To reproduce these effects using the Grandi et al. model (Grandi et al., 2010), we have made a number of changes in these parameters. The most favorable/realistic results were obtained when the maximum conductance for $\mathrm{I}_{\mathrm{Ca}-\mathrm{L}}$ was increased by $20 \%$ and its activation gate was shifted $3 \mathrm{mV}$ in the hyperpolarizing direction (see Equation 2). The changes applied were slightly smaller than the ones reported experimentally, but were sufficient to trigger EADs, as shown in Figure 2.

$$
d_{\infty \_ \text {shifted }}=\frac{1}{1+e^{\frac{V_{m}+5+3}{6}}}
$$

$V_{m}$ is the membrane potential. 


\section{SIMULATION OF RANOLAZINE EFFECTS}

The effects of ranolazine, at an assumed plasma level of 5-10 $\mu \mathrm{M}$, were simulated by decreasing the maximum $\mathrm{I}_{\mathrm{Na}-\mathrm{L}}$ conductance by 50\% (see Figure 4) (cf. Trenor et al., 2013). This maneuver was based on the fact that the recommended adult dosage level for ranolazine is in the 3-8 $\mu \mathrm{M}$ range (Belardinelli et al., 2006).

\section{STIMULATION PROTOCOLS}

AP simulations were conducted at a stimulation rate of $1 \mathrm{~Hz}$. Measurements were taken on stimulated output data only after achieving steady-state conditions.

\section{NUMERICAL IMPLEMENTATION}

All model equations were taken from Grandi et al. (2010), and were implemented in Matlab (Mathworks Inc., Natick, MA, USA). Differential equations were solved numerically using a variable order solver (ode15s) (Shampine and Reichelt, 1997). As indicated, some simulations were performed using O'Hara et al. model, which was also implemented in Matlab. These model equations were downloaded from http://rudylab.wustl.edu, and the rapid integration methods provided in the Supplemental Materials from O'Hara et al. (2011) and one of our previous papers (Trenor et al., 2012) were used.

\section{RESULTS}

The initial set of computations was done for the purpose of illustrating the consequences of the $\mathrm{CO}$ induced changes in mammalian heart $\mathrm{Na}^{+}$current, $\mathrm{I}_{\mathrm{Na}}$ that were described in a primary experimental study. This paper (Dallas et al., 2012) reported that $\mathrm{CO}$ acting through an intracellular NO-mediated signaling cascade can (i) reduce peak $\mathrm{I}_{\mathrm{Na}}$ by as much as $50 \%$ while also (ii) shifting the inactivation curve for the large transient component of $\mathrm{I}_{\mathrm{Na}}$ in hyperpolarizing direction, and (iii) significantly increasing the slowly inactivating component of $\mathrm{I}_{\mathrm{Na}}$ (which is denoted $\mathrm{I}_{\mathrm{Na}-\mathrm{L}}$ ).

The two superimposed human ventricular APs in Figure 1A illustrate the control AP waveform at $1 \mathrm{~Hz}$, and the AP elicited following the changes in $\mathrm{I}_{\mathrm{Na}}$ and $\mathrm{I}_{\mathrm{Na}-\mathrm{L}}$ described above. For these computations, the steady-state inactivation curve was shifted in the hyperpolarizing direction by $5 \mathrm{mV}$ and $\mathrm{I}_{\mathrm{Na}-\mathrm{L}}$ was increased 2 -fold. Figure 1B shows the changes in $\mathrm{I}_{\mathrm{Na}-\mathrm{L}}$; Figure 1C illustrates the indirect effects on $\mathrm{I}_{\mathrm{Ca}-\mathrm{L}}$; that is, the AP waveform lengthened, and this changed the $\mathrm{I}_{\mathrm{Ca}-\mathrm{L}}$; and Figure 1D shows the computed intracellular $\mathrm{Ca}^{2+}$ transient, $\left[\mathrm{Ca}^{2+}\right]_{\mathrm{i}}$.

In summary the reported changes in $\mathrm{I}_{\mathrm{Na}}$ and $\mathrm{I}_{\mathrm{Na}-\mathrm{L}}$, when combined, result in predictable decreases in AP rate-of-rise (not shown) and small increase in AP duration. However, these changes fail to elicit spontaneous firing (EADs on DADs) or produce any correlates of arrythmogenesis. Although this pattern of results was somewhat unexpected, it is important to recall that the primary experimental data on $\mathrm{CO}$ were obtained in rat hearts (Ahern et al., 2000; Dallas et al., 2012), and not from human ventricular tissue or myocytes. We therefore, continued to attempt to illustrate and further understand the electrophysiological effects of $\mathrm{CO}$ on the human ventricular myocardium by considering additional variables.

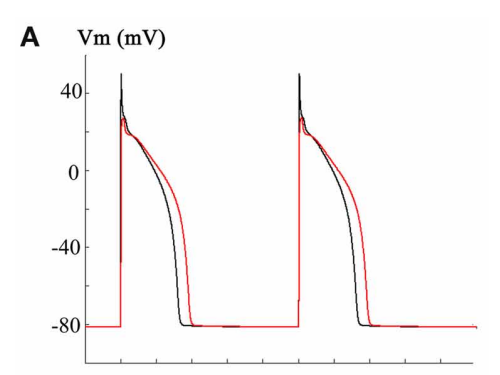

B $\quad \mathrm{I}_{\mathrm{Na}-\mathrm{L}}(\mathrm{pA} / \mathrm{pF})$

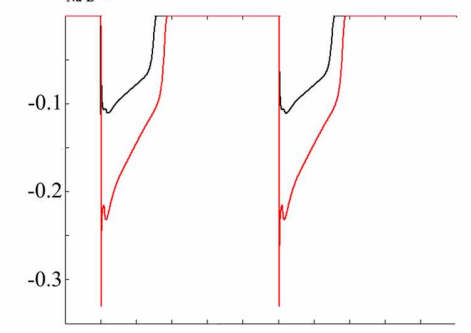

C $\quad \mathrm{I}_{\mathrm{Ca}-\mathrm{L}}(\mathrm{pA} / \mathrm{pF})$

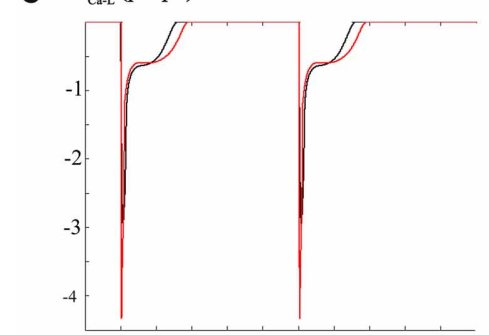

D $\left[\mathrm{Ca}^{2+}\right]_{\mathrm{i}}(\mu \mathrm{M})$

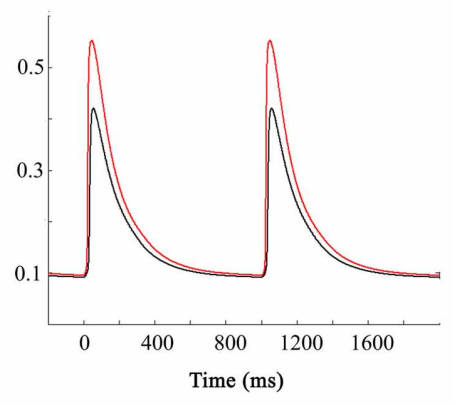

FIGURE 1 | Effects of carbon monoxide (CO) induced changes in $\mathrm{Na}^{+}$ current on the action potential in a human ventricular myocyte. In this and all subsequent Figures, the Grandi et al. mathematical model of the human ventricular action potential was employed (see Methods). Control simulations are shown as black traces and simulations generated by selected changes in model parameters are shown in red. Panel (A) consists of control action potentials (black, $1 \mathrm{~Hz}$., steady state) together with superimposed action potentials (red) that were elicited by the same stimulus parameters after: (i) reducing peak $\mathrm{Na}^{+}$current by $50 \%$, (ii) shifting the steady state inactivation relationship $5 \mathrm{mV}$ in the hyperpolarizing direction, and (iii) altering the mathematical descriptors that govern the slowly inactivating or late sodium current, $I_{\mathrm{Na}-\mathrm{L}}$, such that its size was increased 2-fold. As expected, these changes reduced excitability and decreased the $\mathrm{dV} / \mathrm{dt}$ of the action potential upstroke as well as lengthening the AP at both APD-30 and APD-90. $I_{\mathrm{Na}-\mathrm{L}}$ records are shown in Panel (B). In Panels (C,D) the corresponding L-type $\mathrm{Ca}^{2+}$ current, $\mathrm{I}_{\mathrm{Ca}-\mathrm{L}}$, and intracellular calcium transient, $\left[\mathrm{Ca}^{2+}\right]_{i}$ are illustrated. Note that these changes are indirect, i.e., they result from the changes in APD waveform and the intrinsic biophysical properties of $\mathrm{I}_{\mathrm{Ca}-\mathrm{L}}$ and the $\mathrm{Ca}^{2+}$-induced $\mathrm{Ca}^{2+}$ release (CICR) mechanisms. 
In fact, studies of NO-mediated effects in heterologous expression systems utilizing the alpha subunit of the human heart $\mathrm{Na}^{+}$ channel, $\mathrm{Na}_{\mathrm{v}} 1.5$ (Ueda et al., 2008), reveal a somewhat different pattern of results. These include (i) an (approximately 30\%) increase in peak inward $\mathrm{Na}^{+}$current, a (ii) small hyperpolarizing shift in the steady-state inactivation curve for $\mathrm{I}_{\mathrm{Na}}$, (iii) a marked enhancement (approximately 2 -fold) in $\mathrm{I}_{\mathrm{Na}-\mathrm{L}}$ and (iv) an essential $\mathrm{NO}$-induced S-nitrosylation of a defined residue on $\mathrm{Na}_{\mathrm{v}} 1.5$. These changes, when introduced into the Grandi model, also failed to result in increased arrhythmogenesis (results not shown).

We were aware of the detailed studies of Campbell et al. (1996) on the effects of NO on $\mathrm{I}_{\mathrm{Ca}-\mathrm{L}}$, in the mammalian (ferret) heart. These investigators reported a significant increase in $\mathrm{I}_{\mathrm{Ca}-\mathrm{L}}(30-50 \%)$ under conditions of NO induced S-nitrosylation of this $\mathrm{Ca}^{2+}$ channel $\alpha$-subunit. Importantly, this paper also reported a nitrosylation-induced change in $\mathrm{I}_{\mathrm{Ca}-\mathrm{L}}$ gating, specifically, a small but significant shift in the voltage dependent activation relationship-approximately $6 \mathrm{mV}$ in the hyperpolarizing direction. The superimposed APs in Figure 2 illustrate the consequences of introducing these changes into the original Grandi et al. model (Grandi et al., 2010). Panel (A) shows the AP waveforms (black, baseline, or control) (red, following $\mathrm{I}_{\mathrm{Ca}-\mathrm{L}}$ changes). $\mathrm{I}_{\mathrm{Na}-\mathrm{L}}$ and $\mathrm{I}_{\mathrm{Ca}-\mathrm{L}}$ records are shown in Panels $(\mathrm{B}, \mathrm{C})$, respectively. The L-type $\mathrm{Ca}^{2+}$ current is shown in Panel (C). As shown in Panel (D), these changes in $\mathrm{I}_{\mathrm{Ca}-\mathrm{L}}$ also resulted in a large increase in $\left[\mathrm{Ca}^{2+}\right]_{i}$, and the $\left[\mathrm{Ca}^{2+}\right]_{i}$ exhibited pronounced frequency dependence or alternans (see Discussion and Clark et al., 1996; Bouchard et al., 2004).

Detailed inspection of Figure 2 and comparison of this pattern of results with those in Figure 1 reveal (Panel B) that $\mathrm{I}_{\mathrm{Na}-\mathrm{L}}$ now shows pronounced changes in peak amplitude, even in response to the fixed stimulus rate at $1 \mathrm{~Hz}$. Presumably, this arises from the markedly prolonged AP and intrinsic voltage-dependence of reactivation of $\mathrm{I}_{\mathrm{Na}-\mathrm{L}}$ ( see Discussion).

The third set of computations in this study combined the reported $\mathrm{CO}$ induced changes in $\mathrm{I}_{\mathrm{Na}}$ and $\mathrm{I}_{\mathrm{Na}-\mathrm{L}}$ (Figure 1), with those for $\mathrm{I}_{\mathrm{Ca}-\mathrm{L}}$ (Figure 2). The resulting very significant changes in AP duration (Panel A), $\mathrm{I}_{\mathrm{Na}-\mathrm{L}}\left(\right.$ Panel B), $\mathrm{I}_{\mathrm{Ca}-\mathrm{L}}$ (Panel C), and $\left[\mathrm{Ca}^{2+}\right]_{\mathrm{i}}$ (Panel D) are shown in Figure 3. This pattern of results was similar to, but not identical with Figure 2. In particular, the majority of the APs elicited at a physiological stimulus rate $(1 \mathrm{~Hz})$ exhibited marked prolongation (approximately 100\%), with the appearance of an EAD late in the prolonged plateau phase. Note that under these starting conditions, the combined inward currents due to $\mathrm{I}_{\mathrm{Na}-\mathrm{L}}$ and $\mathrm{I}_{\mathrm{Ca}-\mathrm{L}}$ "held" the membrane potential of the plateau near $0 \mathrm{mV}$ in contrast with the approximately $-10 \mathrm{mV}$ plateau level in Figure 2.

The pattern of changes shown in Figure 3 is not surprising. It is now well known that abnormal, slow depolarizations, which are denoted EADs, can be elicited by changes in $\mathrm{I}_{\mathrm{Ca}-\mathrm{L}}$ (Marban et al., 1986; January and Riddle, 1989, for review see Clusin, 2003). In fact, in rabbit ventricle a recent report from the Weiss laboratory (Madhvani et al., 2011) has illustrated in detail ways in which even very small changes in the voltage dependence of the activation of $\mathrm{I}_{\mathrm{Ca}-\mathrm{L}}$ can give rise to EADs. This is mainly, but not entirely due to the fact that there is an increased inward current at or very
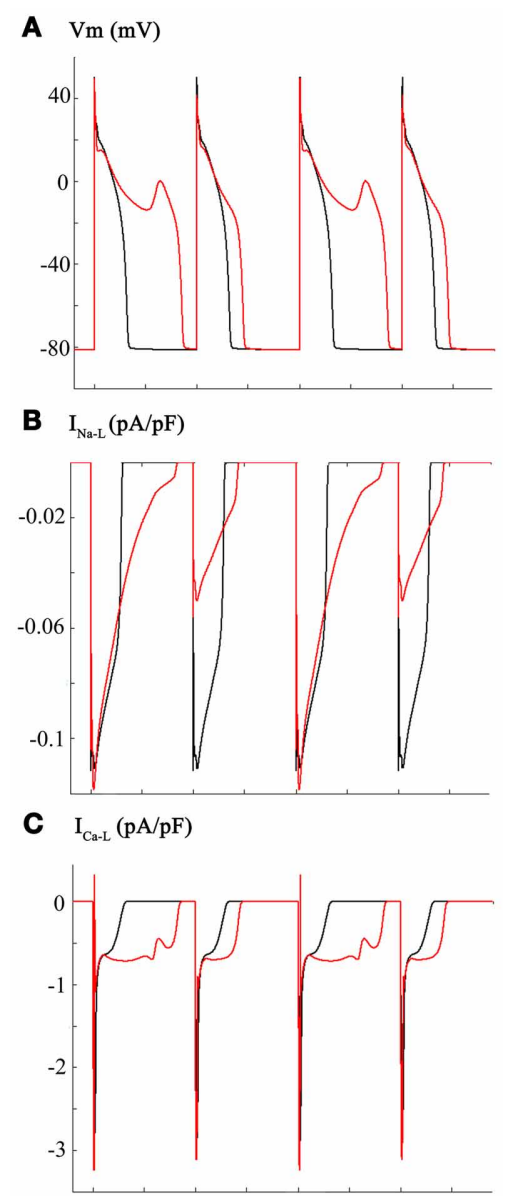

D $\left[\mathrm{Ca}^{2+}\right]_{\mathrm{i}}(\mu \mathrm{M})$

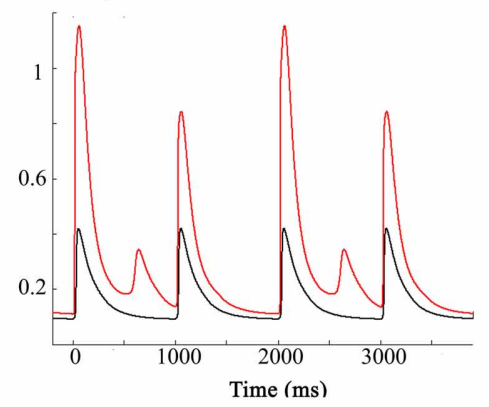

FIGURE 2 | Effects of CO-induced changes in L-type $\mathrm{Ca}^{2+}$ current on the human ventricular myocyte. Based on the work of Campbell et al., $I_{\text {Ca-L }}$ was increased $50 \%$ and the voltage dependence for the activation curve was shifted in the depolarizing direction by $3 \mathrm{mV}$. As shown in Panel (A) these changes resulted in a lengthening of the action potential plateau and appearance of associated oscillatory potentials or early after depolarizations (EADs). Panel (B) shows the changes in $I_{\mathrm{Na}-\mathrm{L}}$. The longer APD results in a protracted $I_{\mathrm{Na}-\mathrm{L}}$; the alterations in amplitude of this current are due to the voltage dependence of its reactivation. As shown in Panel (C), these changes in the biophysical parameters that regulate $\mathrm{I}_{\mathrm{Ca}} \mathrm{L}$ resulted in a change in peak amplitude and perhaps more importantly a significant alteration in its time course of inactivation. I Ca-L $L_{\text {also reactivates }}$ under these conditions. Panel (D) shows the control $\mathrm{Ca}^{2+}$ transient and the computed changes in $\left[\mathrm{Ca}^{2+}\right]_{i}$ that occur as a consequence of alterations in the $\mathrm{I}_{\mathrm{Ca}-\mathrm{L}}$. 


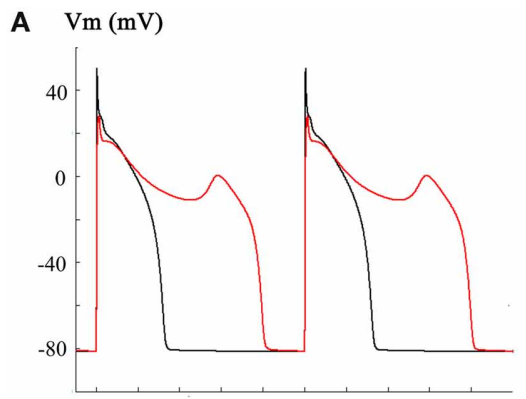

B $\quad \mathrm{I}_{\mathrm{Na}-\mathrm{L}}(\mathrm{pA} / \mathrm{pF})$

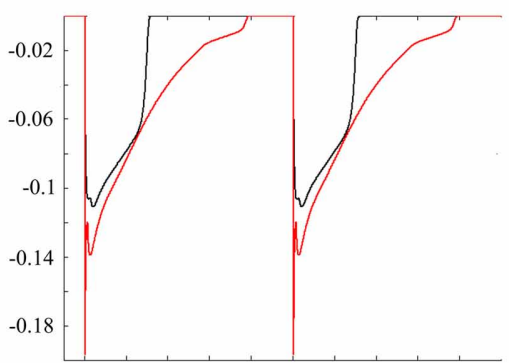

C $\mathrm{I}_{\mathrm{Ca}-\mathrm{L}}(\mathrm{pA} / \mathrm{pF})$

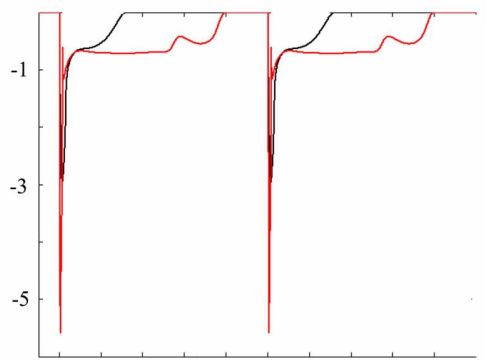

D $\left[\mathrm{Ca}^{2+}\right]_{\mathrm{i}}(\mu \mathrm{M})$

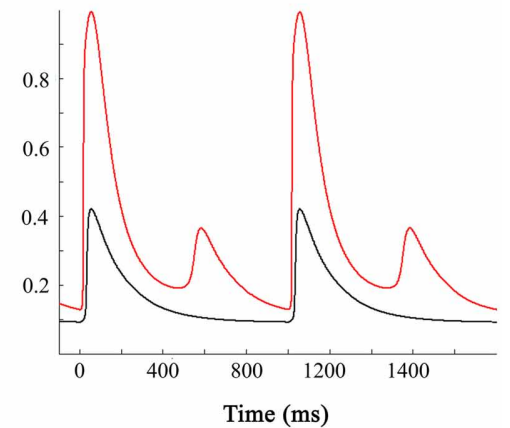

FIGURE 3 | Changes in the human ventricular action potential as a consequence of $\mathrm{CO}$-induced changes in both $\mathrm{I}_{\mathrm{Na}}$ and $\mathrm{I}_{\mathrm{Ca}-\mathrm{L} \text {. The layout }}$ and color-coding of this Figure is identical to that described for

Figures 1, 2. As shown in Panel (A) when the CO-induced changes in $\mathrm{Na}^{+}$and $\mathrm{Ca}^{2+}$ currents are combined there is marked lengthening of the action potential and a significantly increased incidence and frequency of EADs occurring during the somewhat depolarized plateau phase of the action potential. $I_{\text {Na-L }}$ records are shown in Panel (B). Panels (C,D) show the changes in $\mathrm{I}_{\mathrm{Ca}-\mathrm{L}}$ and $\left[\mathrm{Ca}^{2+}\right]_{\mathrm{i}}$. Note that the changes in $\mathrm{I}_{\mathrm{Ca}-\mathrm{L}}$ differ from those in Figure 2 as a result of the alterations in action potential waveform caused by the combined changes in $\mathrm{I}_{\mathrm{Na}}$ and $\mathrm{I}_{\mathrm{Ca}-\mathrm{L}}$.
A $\operatorname{Vm}(\mathrm{mV})$

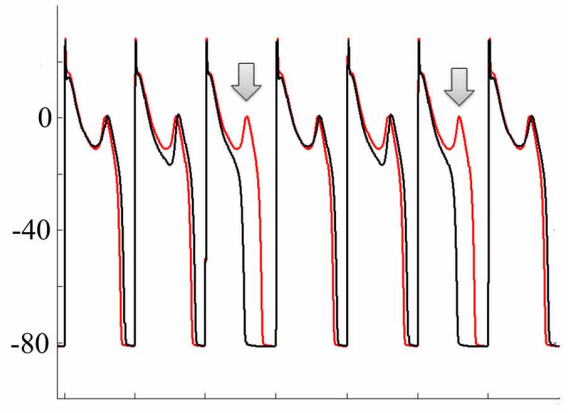

B $\left[\mathrm{Ca}^{2+}\right]_{\mathrm{i}}(\mu \mathrm{M})$
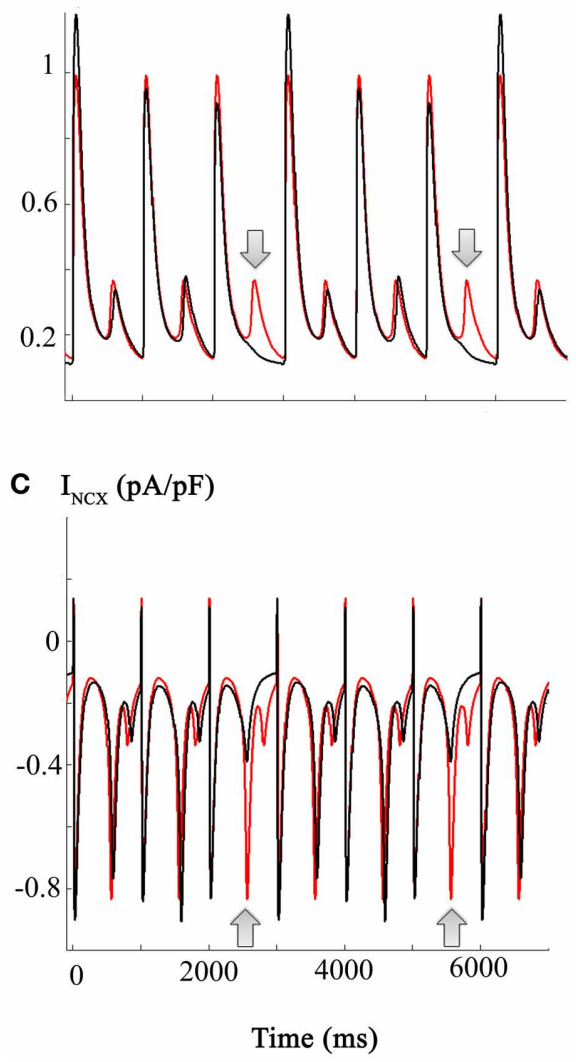

FIGURE 4 | Estimation and illustration of the effects of ranolazine on CO-induced changes in the action potential and underlying $\mathrm{I}_{\mathrm{Na}-\mathrm{L}}$,

$I_{C a-L}$, and $\mathrm{Na}^{+} / \mathrm{Ca}^{2+}$ exchange currents $\left(\mathrm{I}_{\mathrm{NCX}}\right)$ in human ventricle. The effects of ranolazine (shown in black) were modeled as a selective 50\% reduction in the $\mathrm{I}_{\mathrm{Na}-\mathrm{L}}$. Note that this reduces action potential, duration of every 3rd action potential, as well as decreasing the incidence and the frequency of EADs. However, these changes are complex. APD (Panel A) as well as $\left[\mathrm{Ca}^{2+}\right]_{i}$ and $I_{\mathrm{NCX}}$ records all show variations or alternans, even at this fixed stimulus rate $(1 \mathrm{~Hz})$. Panel $\mathbf{( C )}$ illustrates the corresponding ranolazine-induced changes in the $I_{\mathrm{NCX}}$. Note that in the action potential traces showing a ranolazine-induced shortening of APD, there is no spontaneous inward $I_{\text {NCX }}$ current (see also Figure $\mathbf{5}$ and Results). The arrows denote the "extra" EADs (Panel A), and underlying $\left[\mathrm{Ca}^{2+}\right]_{i}$ transient (Panel B), and $I_{\text {NCX }}$ (Panel C) records. 
near the range of membrane potentials of the plateau of the normal or prolonged AP. The underlying biophysical mechanism(s) involves the non-linear interactions of the small overlapping $\mathrm{Ca}^{2+}$ channel-and $\mathrm{Na}^{+} / \mathrm{Ca}^{2+}$ _exchanger mediated currents in this range of membrane potentials (Madhvani et al., 2011, for review see Fink et al., 2006). The altered AP waveform and related proor anti-arrhythmic effects are sometimes described in terms of an altered "repolarization reserve" at defined time-points of early or late repolarization (Wu et al., 2009; Varró and Baczkó, 2011; Trenor et al., 2013).

If environmental or tissue-derived $\mathrm{CO}$ can induce lifethreatening ventricular rhythm disturbances through a mechanism involving enhancement of $\mathrm{I}_{\mathrm{Na}-\mathrm{L}}$, it is plausible that, as mentioned in the Introduction, ranolazine could be effective in Critical Care settings (Dallas et al., 2012, cf. Belardinelli et al., 2006; Bell et al., 2009). The mathematical simulations shown in Figure 4 address this possibility by illustrating the effects of ranolazine "in silico." These computations were carried out under starting conditions (i.e., an initial parameter set) almost identical to those for Figure 3. However, for these computations it was assumed that ranolazine actions would be the equivalent of a 50\% reduction of the $\mathrm{CO}$ induced increase in $\mathrm{I}_{\mathrm{Na}-\mathrm{L}}$ (see Figure 1). The results show that if ranolazine (at an assumed plasma level of $5 \mu \mathrm{M}$ ) did block approximately $50 \%$ of $\mathrm{I}_{\mathrm{Na}-\mathrm{L}}$, it could shorten the AP elicited by a $1 \mathrm{~Hz}$ train of stimuli. Note, however, that this partial block of $\mathrm{I}_{\mathrm{Na}-\mathrm{L}}$ reduced APD only (approximately) every 3rd AP in this $1 \mathrm{~Hz}$ AP train. An additional effect is also apparent: reducing $\mathrm{I}_{\mathrm{Na}-\mathrm{L}}$ changes the (i) waveform and (ii) the most negative membrane potential in some repolarizing components within this train of AP's. This primary "effect" appears to be linked functionally to the approximately normal repolarization of the next AP. In summary, when ranolazine is introduced in silico, the resulting AP waveforms show complex alternating patterns. However, there is an increased number of (i) near normal AP waveforms and (ii) monotonic $\left[\mathrm{Ca}^{2+}\right]_{\mathrm{i}}$ records. The incidence of EADs is also reduced, consistent with the previously described actions of this drug in the settings of free radical challenge, genetic abnormalities in $\mathrm{Na}^{+}$channel biophysics, hypoxia, or global ischemia/heart failure (Fink et al., 2006; Trenor et al., 2012).

The simulations in Figure 5 address and attempt to illustrate some of the underlying causative factors for $\mathrm{EAD}$ generation within the framework/limitations of this model of the human ventricle AP. EAD generation requires the membrane potential to be relatively depolarized, so that L-type $\mathrm{Ca}^{2+}$ channels can be activated and contribute a small but significant inward $\mathrm{Ca}^{2+}$ current. We note that the main interacting (or overlapping) ion channel mediated currents at the plateau of the AP are: (i) $\mathrm{I}_{\mathrm{Na}-\mathrm{L}}$, (ii) $\mathrm{I}_{\mathrm{Ca}-\mathrm{L}}$, (iii) $\mathrm{I}_{\mathrm{K} 1}$, a time-independent or background inwardly rectifying current, and (iv) the delayed rectifier $\mathrm{K}^{+}$current, $\mathrm{I}_{\mathrm{K}-\mathrm{R}}$ (Trenor et al., 2013). In the presence of an enhanced $\mathrm{I}_{\mathrm{Na}-\mathrm{L}}$ the AP plateau is somewhat depolarized and the AP tends to be prolonged. In addition, under these conditions $\mathrm{I}_{\mathrm{NCX}}$ generated by the $\mathrm{Na}^{+} / \mathrm{Ca}^{2+}$ exchange mechanism can be functionally important. A key question is: are the pronounced changes in $\left[\mathrm{Ca}^{2+}\right]_{\mathrm{i}}$ the cause or the consequence of the EAD/CO-induced pro-arrhythmic substrate. A plausible answer can be obtained by consideration of the results in Panels (A-F) of Figure 5.
Panel (A) shows two superimposed pairs of APs, each elicited at steady state $(1 \mathrm{~Hz})$ before (black) and after (red) introducing the changes shown in Figure 3. Panels $(B, C)$ show the corresponding $\mathrm{I}_{\mathrm{Na}-\mathrm{L}}$ and $\mathrm{I}_{\mathrm{Ca}-\mathrm{L}}$ records. Although this information is redundant with that in Figure 3: here, it provides a means for direct comparison with the new data: Panel (D), $\left[\mathrm{Ca}^{2+}\right]_{\mathrm{i}}$ records; Panel (E), $\mathrm{I}_{\mathrm{NCX}}$; and Panel $(\mathrm{F})$, the $\mathrm{Ca}^{2+}$ content of the SR.

Taken together, these results suggest that in this model the $\mathrm{CO} / \mathrm{NO}$-induced changes in $\mathrm{I}_{\mathrm{Ca}-\mathrm{L}}$ are critical. With each stimulus, a large "extra" $\mathrm{Ca}^{2+}$ influx prolongs the plateau and results in enhanced $\mathrm{Ca}^{2+}$ release and a much larger increase in $\left[\mathrm{Ca}^{2+}\right]_{\mathrm{i}}$. This change in $\left[\mathrm{Ca}^{2+}\right]_{\mathrm{i}}$ can stimulate the $\mathrm{I}_{\mathrm{NCX}}$. Perhaps more importantly, however, this time-dependent and cumulative change in myocyte $\mathrm{Ca}^{2+}$ homeostasis results in markedly increased $\mathrm{Ca}^{2+}$ in the SR. Eventually, this causes anomalous $\mathrm{Ca}^{2+}$ release from the $\mathrm{SR}$, and the $\mathrm{Na}^{+} / \mathrm{Ca}^{2+}$ exchanger (denoted by arrows) responds by generating an inward current that gives rise to the EAD. Under these conditions, approximately every second AP is associated with spontaneous release at the steady-state stimulus rate of $1 \mathrm{~Hz}$.

This scheme/scenario seems plausible, since similar patterns of changes have been described experimentally. However, it may not be readily apparent how ranolazine, acting only on $\mathrm{I}_{\mathrm{Na}-\mathrm{L}}$ could be anti-arrhythmic (see Discussion). In brief, the answer appears to be that ranolazine, by blocking $\mathrm{I}_{\mathrm{Na}-\mathrm{L}}$, can shorten the AP. This reduction in APD results in reduced $\mathrm{Ca}^{2+}$ influx through $\mathrm{I}_{\mathrm{Ca}-\mathrm{L}}$ during each AP and thus, there is less $\mathrm{Ca}^{2+}$-loading of the SR. The end result is that $\mathrm{SR} \mathrm{Ca}^{2+}$ content does not reach the abnormal levels required for anomalous and spontaneous $\mathrm{Ca}^{2+}$ release. Hence, there is no intracellular $\mathrm{Ca}^{2+}$ "trigger" for the electrogenic $\mathrm{I}_{\mathrm{NCX}}$, that has an important role in initiating the EAD in this model (Houser, 2000; Clusin, 2003).

\section{DISCUSSION}

\section{SUMMARY OF MAIN FINDINGS}

Our mathematical modeling illustrates one set of conditions under which human ventricle myocytes can respond to a significant $\mathrm{CO}$ induced challenge (environmental or intrinsic) by generating an aberrant cellular electrophysiological pattern of responses, denoted EADs.

When using a modified Grandi et al. modeling framework (Grandi et al., 2010), the reported (Dallas et al., 2012) changes in $\mathrm{Na}^{+}$current following $\mathrm{CO}$ exposure were not sufficient to provide the required pro-arrhythmic substrate. Additional changes in $\mathrm{I}_{\mathrm{Na}-\mathrm{L}}$ parameters may have given rise to $\mathrm{EAD}$ waveforms. However, we evaluated the possibility that other ion channel targets were involved in EAD initiation. Accordingly, our analyses of CO-induced EADs include changes in $\mathrm{I}_{\mathrm{Na}-\mathrm{L}}$ and $\mathrm{I}_{\mathrm{Ca}-\mathrm{L}}$. As shown in Figure 2, even very small changes in $\mathrm{I}_{\mathrm{Ca}-\mathrm{L}}$ can produce EAD generation. Although this pattern of results has not been reported when $\mathrm{CO}$ is used as the "toxic" stimulus; it is known that $\mathrm{NO}$ is a primary mediator of CO-induced pro-arrhythmic events in the heart (Dallas et al., 2012). Campbell et al. (1996) have established that NO driven S-nitrosylation can modify $\mathrm{I}_{\mathrm{Ca}-\mathrm{L}}$. We adopted this approach and were guided by this comprehensive biophysical/molecular pharmacological data set. 

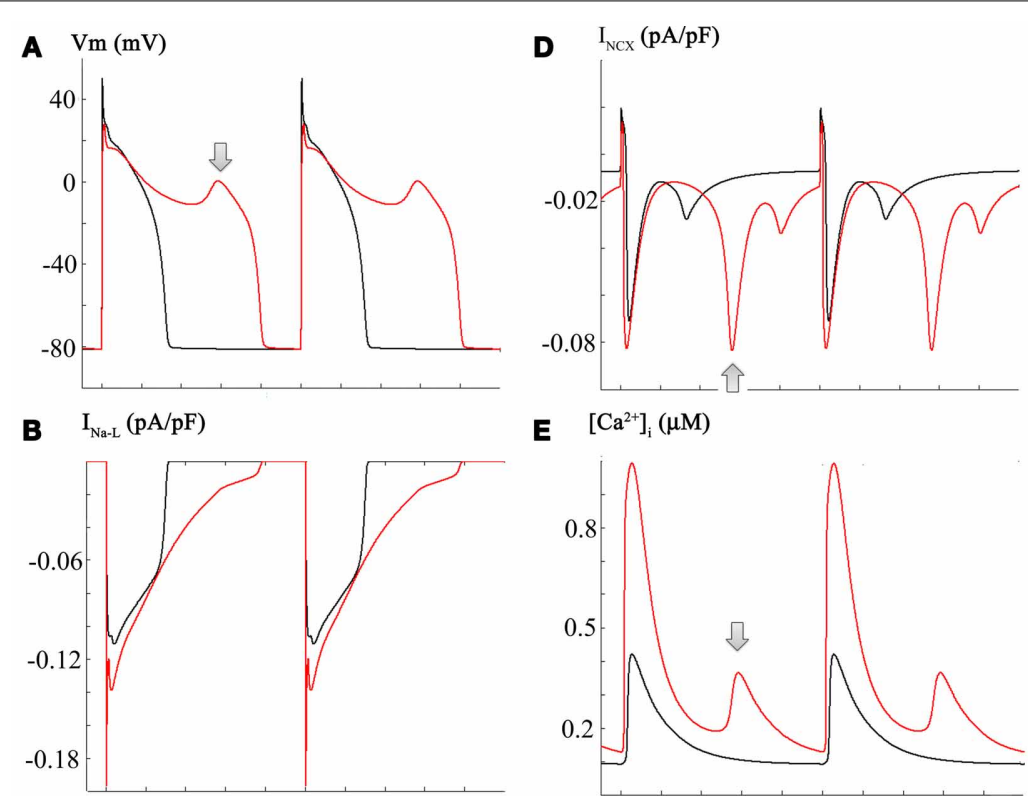

E $\left[\mathrm{Ca}^{2+}\right]_{\mathrm{i}}(\mu \mathrm{M})$
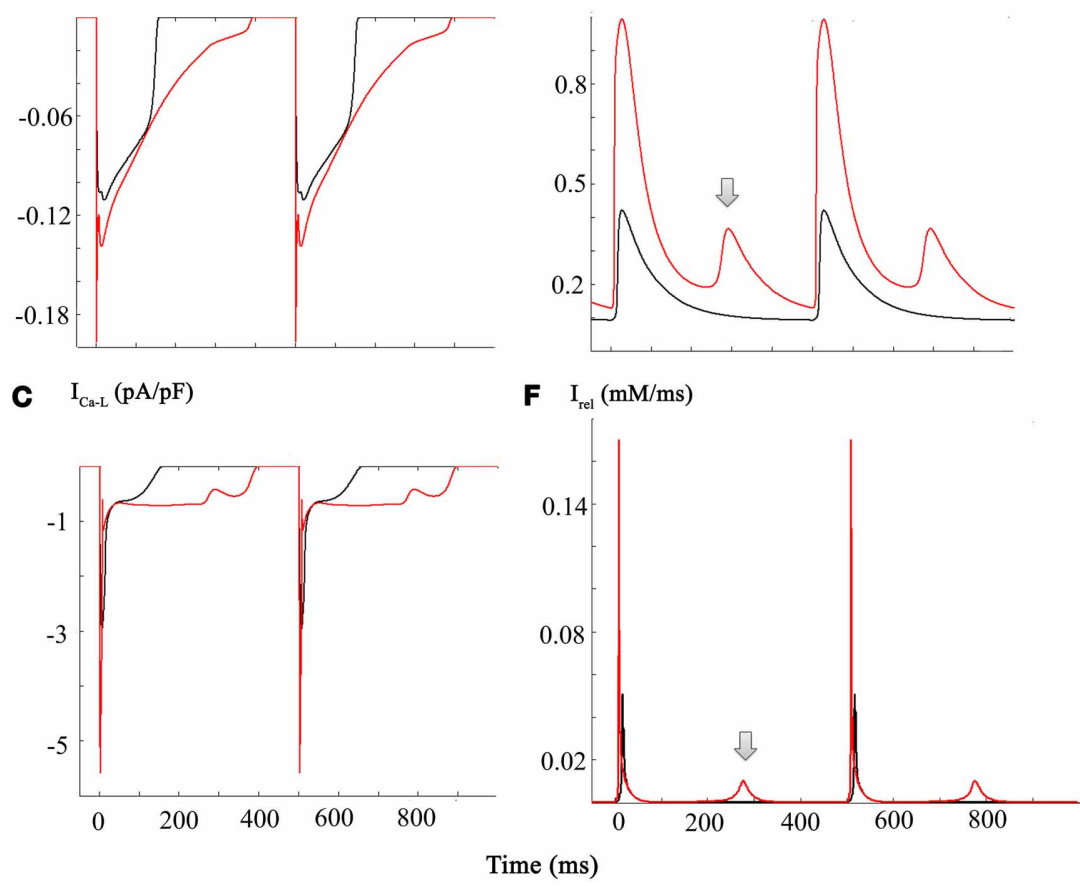

FIGURE 5 | Diagram illustrating a plausible mechanism for generation of EADs in our modified Grandi model of the human ventricular action potential. Panels ( $\mathbf{A}$ through $\mathbf{C}$ ) each consist of a pair of superimposed records for the $A P, I_{N a-L}$, and $I_{C a-L}$ records, respectively. Those in black correspond to control or baseline conditions, and the CO-induced changes are shown in red. Important new information is illustrated in the corresponding (i) $I_{\text {NCX }}$ currents, Panel (D); (ii) $\left[\mathrm{Ca}^{2+}\right]_{\mid}$data, Panel $(\mathbf{E})$; and the current generated by $\mathrm{Ca}^{2+}$ release from the sarcoplasmic reticulum $I_{\text {rel, }}$ Panel (F). The arrows denote the EAD (Panel $\mathbf{A}$ ) and underlying spontaneous $\mathrm{Ca}^{2+}$ release from the SR (Panel $\mathbf{F}$ ) and $I_{N C X}$ current driven by the increase in $\left[\mathrm{Ca}^{2+}\right]_{i}$ (Panel E). Refer to Results and Discussion sections for further details and explanation.
It is interesting that in spite of an apparent "double hit" being required for the initiation of EADs, in silico, reduction of only one of these contributing factors, a $50 \%$ decrease of $\mathrm{I}_{\mathrm{Na}-\mathrm{L}}$, resulted in a reduction in the EAD incidence (see Figure 4). This is consistent with the experimental observation that selective pharmacological inhibition of $\mathrm{I}_{\mathrm{Na}-\mathrm{L}}$ can serve as an antidote to $\mathrm{CO}$-induced rhythm disturbances in rat ventricle (Dallas et al., 2012).

\section{MECHANISTIC INSIGHTS}

Some aspects of the cellular/biophysical mechanism(s) responsible for EAD generation can be deduced/confirmed by careful inspection of the new data from our simulations. EADs are slow, small depolarizations that arise in the ventricle (and in Purkinje tissue) within a transmembrane voltage range corresponding to the plateau of the ventricular AP (approximately -10 to $+10 \mathrm{mV}$ ). A net inward current is required, and the work from the Marban (Marban et al., 1986) and January (January and Riddle, 1989) Laboratories has established that there is an obligatory requirement for activation of $\mathrm{I}_{\mathrm{Ca}-\mathrm{L}}$. In fact, $\mathrm{I}_{\mathrm{Ca}-\mathrm{L}}$, in most cases, must reactivate. That is, a small fraction of the same $\mathrm{I}_{\mathrm{Ca}-\mathrm{L}}$ channels that have opened previously in the AP to produce the distinctive plateau of the human ventricular AP open again. This produces a "pedestal" or apparently non-inactivating $\mathrm{I}_{\text {Ca-L }}$ component (Corrias et al., 2011). Our simulations are interesting in this regard. Detailed inspection of Figures 2-4 in fact show that EAD generation in this model occurs at a time when the $\mathrm{I}_{\mathrm{Ca}-\mathrm{L}}$ pedestal shows a small, transient decrease. In the Grandi et al. model, this is due to the specific mathematical expression of $\left[\mathrm{Ca}^{2+}\right]_{\mathrm{i}}$ dependent inactivation that is employed. 
However, the non-inactivating component of $\mathrm{I}_{\mathrm{Ca}-\mathrm{L}}$ and the inward current due to $\mathrm{I}_{\mathrm{Na}-\mathrm{L}}$ markedly prolong the $\mathrm{AP}$, and this change in APD waveform results in a significant increase in $\mathrm{Ca}^{2+}$ influx since $\mathrm{I}_{\mathrm{Ca}-\mathrm{L}}$ does not fully inactivate. This extra $\mathrm{Ca}^{2+}$ influx, results in a time-dependent and marked increase in SR $\mathrm{Ca}^{2+}$ content. Eventually this causes a spontaneous and intermittent (anomalous) pattern of SR $\mathrm{Ca}^{2+}$ release. Each of these increases in $\left[\mathrm{Ca}^{2+}\right]_{i}$ gives rise to a significant "new" inward current generated by the sarcolemmal $\mathrm{Na}^{+} / \mathrm{Ca}^{2+}$ exchanger mechanism.

It is worth noting that during $\mathrm{CO}$ challenge (intoxication and recovery) or in any setting involving stress, the known effects of stimulation of the sympathetic nervous system would be expected to augment both $\mathrm{Na}^{+}$and $\mathrm{Ca}^{2+}$ currents. These changes, alone or in combination, would enhance $\mathrm{I}_{\mathrm{Ca}-\mathrm{L}}$ and perhaps $\mathrm{I}_{\mathrm{Na}-\mathrm{L}}$, both of which would contribute a net inward current at the plateau level of the ventricular AP. The Koren Laboratory (Liu et al., 2012) has recently developed a robust model of EAD induced arrhythmias based on genetically targeted malfunction of distinct repolarizing $\mathrm{K}^{+}$currents in adult rabbit ventricle. Their findings provide interesting insights into underlying mechanisms of pro-arrhythmic impulse generation at relatively depolarized (AP plateau) levels in the ventricular myocardium. Specifically, they have reported enhanced EAD activity either (i) following augmentation of $\mathrm{I}_{\mathrm{Ca}-\mathrm{L}}$ with isoproterenol, or (ii) a reduction of repolarizing $\mathrm{K}^{+}$current(s) during hypokalemic conditions. Both of these maneuvers can alter the net current at the plateau of the AP and thus, change the repolarization reserve during the early repolarization phase of the AP (cf. Fink et al., 2006; Sarkar and Sobie, 2011; Trenor et al., 2012). Further insights into the ionic mechanisms responsible for EAD initiation and maintenance requires definition of, and agreement on, the range of membrane potentials at which those small oscillating events occur (Gaur et al., 2009).

\section{FUTURE DIRECTIONS}

As indicated in the Introduction, there are a number of additional targets or sites, at which CO or CO-generated signaling molecules are known to act. Perhaps the most important of these are the $\mathrm{K}^{+}$ currents that are expressed throughout the mammalian heart, and have important roles in setting the resting potential and modulating repolarization. The Tamargo Group (Gómez et al., 2009) has shown that the $\mathrm{K}^{+}$conductance which underlies the resting potential in atrium and ventricle, $\mathrm{K}_{\mathrm{ir}} 2.1$ or $\mathrm{I}_{\mathrm{K} 1}$, is a target for S-nitrosylation. This chemical modification of this current results in increased $\mathrm{I}_{\mathrm{K} 1}$. Although $\mathrm{I}_{\mathrm{K} 1}$ is non-linear, it increases the repolarization reserve during final repolarization, and may cause a small $(1-3 \mathrm{mV})$ hyperpolarization of the resting potential (cf. Fink et al., 2006). More detailed studies of CO effects should include this target of CO-mediated channel effects.

Tamargo et al. (Núñez et al., 2006) have also reported that a prominent repolarizing current in the atrium of most mammalian species, $\mathrm{K}_{\mathrm{v}} 1.5$, can be altered by S-nitrosylation. $\mathrm{K}_{\mathrm{v}} 1.5$ is decreased by $\mathrm{S}$-nitrosylation, and this would be pro-arrhythmic. We note however, that $K_{v} 1.5$ is a small current in human ventricle (cf. Fink et al., 2006; Grandi et al., 2010).

As noted in the Introduction, the Makielski Group (Ueda et al., 2008) has reported that NO and an associated S-nitrosylation modification of $\mathrm{I}_{\mathrm{Na}}$ can result in a significantly enhanced $\mathrm{I}_{\mathrm{Na}-\mathrm{L}}$. In fact, however, their investigation focused on $\mathrm{NO}$ effects on $\mathrm{I}_{\mathrm{Na}}$ in the setting of an identified mutation in syntrophin that results in one variant of a pattern of ventricular rhythm disturbances, denoted the long Q-T syndrome (cf. Moss et al., 2008; Thomas et al., 2008).

It has been proposed (Dallas et al., 2012) that consideration should be given to utilization of ranolazine or ranolazinelike compounds in clinical settings (Emergency or Critical Care Medicine) that involve documented CO poisoning and involve ventricular rhythm disturbances. Improved clinical interventions directed toward minimizing cardiac risk during the required recovery period from $\mathrm{CO}$ intoxication are much needed (Goldstein, 2008; Motterlini and Otterbein, 2010). In principle, and as illustrated, ranolazine or ranolazine-like compounds could be considered for this purpose (Belardinelli et al., 2006; Kinobe et al., 2008; Saint, 2008; Wu et al., 2009). Ranolazine quite selectively targets $\mathrm{I}_{\mathrm{Na}-\mathrm{L}}$. However, the net current change that is the direct result of ranolazine interaction with $\mathrm{Na}^{+}$channel, is integrated in the overall cardiac electrophysiological system (biophysical mechanism) for maintenance and generation of the plateau of the AP, in a way that involves complex, often non-linear interactions of a number of different currents (Fink et al., 2006). Thus, a monotonic dose-response relationship for ranolazine effects is not anticipated in this type of clinical/therapeutic setting/application and individual differences in the electrophysiological substrate are expected to/need to continue to be considered (Sarkar et al., 2012).

The computations presented in this paper have all been carried out assuming that the $\mathrm{CO}$ target is a single ventricular myocyte. Although this is a valid starting point, it is known that the isolated single human ventricular myocyte has electrophysiological characteristics somewhat different than the same myocyte functionally joined to other myocytes through gap junction or "placed" in a syncytium consisting of many other similar or identical myocytes. Often, the AP waveform in the syncytium is slightly but significantly different than that in a single cell. For example, the plateau "height" is less depolarized in the syncytium. Intracellular current flow, and other factors, such as intrinsic electrophysiological heterogeneity of the myocytes, can also result in the AP of a myocyte within a syncytium having a more stable resting potential together with much less intrinsic action APD variability (Huelsing et al., 2000; Zaniboni et al., 2000; Spitzer et al., 2006). In addition, it is now known that in both the ventricular and the atrial myocardium the fibroblast/myofibroblast cell population (Wu and Wang, 2005) may produce significant electrotonic effects (Maleckar et al., 2009, cf. Baudino et al., 2006). It is possible that either $\mathrm{CO}$ or its immediate downstream signaling molecules could alter fibroblast electrophysiology/paracrine function. One or more of these factors may alter the pattern of response which we have observed in our in silico investigation of $\mathrm{CO}$ effects.

\section{LIMITATIONS}

We are aware that as presented our analysis of $\mathrm{CO}$ effects on the human ventricle is incomplete. Primary reasons for this include: 
1. The computational platform that we have used is comprehensive and has been tested in terms of its ability to illustrate the functional roles of many of the individual ion channel currents that underlie the AP. However, it and most other such models have limitations. In this paper, we illustrate pronounced effects on AP waveforms and pro-arrhythmic patterns of response that arise from very small current changes that would be consistent with CO effects. The Grandi model (Grandi et al., 2010) can be relied on as a computational platform for human ventricular myocytes when exploring problems that can be addressed with semi-quantitative endpoints. However, caution is warranted when the input data suggests only e.g., a $1-3 \mathrm{mV}$ shift in an activation parameter (cf. Terkildsen et al., 2008).

2. It is apparent that simulation of CO-mediated electrophysiological effects requires detailed understanding of each major component of $\mathrm{Ca}^{2+}$ homeostasis in the human ventricular myocyte. Recent publications show that S-nitrosylation can alter ryanodine receptor function and change $\mathrm{Ca}^{2+}$-induced $\mathrm{Ca}^{2+}$ release (Ahern et al., 2000; Wang et al., 2010; Cutler et al., 2012). Our work does not address this possibility. In fact, in the Grandi et al. modeling environment (Grandi et al., 2010) detailed studies of the consequences of changes in $\mathrm{Ca}^{2+}$-induced $\mathrm{Ca}^{2+}$ release (CICR) are not possible since many of the known subcellular details of CICR release are not included in this computational platform. After this model is developed further and e.g., the existing electrophysiological components are integrated with known properties of E-C coupling and mechanical activation (Tao et al., 2011), further insights into CO-mediated effects may be able to be obtained and $\mathrm{Ca}^{2+}$-pump (SERCA 2) mediated relaxation.

3. Detailed studies of CO-mediated alterations of mammalian cardiac electrophysiological phenomena are relatively recent. At present, there is incomplete information on clinically relevant plasma levels, interspecies variations, and specific intracellular signaling cascades. This information is essential for more extensive simulations that could address cellular or molecular mechanisms for $\mathrm{CO}-\mathrm{I}_{\mathrm{Na}}-\mathrm{NO}$ interactions (Ueda et al., 2008), including those arising from ion channel mutations (Thomas et al., 2008) or changes in intercellular coupling (Haas and Landisman, 2011), identification or selection of therapeutic agents, and improvement of Systems Biology (Winslow et al., 2011) approaches to human cardiac sudden death in humans.

4. Our work is not intended to detract from or replace wellestablished principles of CO generation or action (Maines, 1997) based on the heme oxygenase system. However, two

\section{REFERENCES}

Abramochkin, D. V., Haertdinov, N. N., Porokhnya, M. V., Zefirov, A. L., and Sitdikova, G. F. (2011). Carbon monoxide affects electrical and contractile activity of rat myocardium. J. Biomed. Sci. 18:40. doi: 10.1186/1423-012718-40

Ahern, G. P., Hsu, S. F., Klyachko, V. A., and Jackson, M. B. (2000).
Induction of persistent sodium current by exogenous and endogenous nitric oxide. J. Biol. Chem. 275, 28810-28815. doi: 10.1074/jbc. M003090200

Baudino, T., Carver, W., Giles, W., and Borg, T. K. (2006). Cardiac fibroblasts: friend or foe? Am. J. Physiol. Heart Circ. Physiol. 291, H1015-H1026. doi: 10.1152/ ajpheart.00023.2006

points are noteworthy. (i) It is now known that an essential site of action of $\mathrm{CO}$ in resistance vessels is a reduced heme moiety that is co-localized with the $\mathrm{Ca}^{2+}$-activated $\mathrm{K}^{+}$channels that modulate CO-induced vasodilation (Jaggar et al., 2005). (ii) $\mathrm{CO}$ challenge results in compromised haemoglobin function and pronounced hypoxia. Hypoxia is an established condition that results in augmented $\mathrm{I}_{\mathrm{Na}-\mathrm{L}}$ in the myocardium (Ju et al., 1996). A recent paper advances an interesting plausible scenario in which micro-anatomical integration, that is co-expression of $\mathrm{Na}^{+}$channels, $\mathrm{NO}$ synthase isoform and $\mathrm{G}$ proteins are co-localized in caveolae (Besse et al., 2011).

5. Our approach to the pro-arrhythmic effects of CO challenge has placed an emphasis on EAD initiation. We acknowledge that alterations in micro- or macroscopic conduction patterns or velocities; and/or $\mathrm{I}_{\mathrm{Na}}, \mathrm{I}_{\mathrm{Na}-\mathrm{L}}$, and $\mathrm{I}_{\mathrm{Ca}-\mathrm{L}}$ dependent changes in AP waveform have not been ruled out as plausible proarrhythmic elements. These, along with the S-nitosylation induced change in mammalian heart $\mathrm{K}^{+}$currents (Gómez et al., 2009; Tamargo et al., 2010), could form the basis of a more comprehensive study, after sufficient data from one mammalian species, preferably human, is obtained.

\section{AUTHOR CONTRIBUTIONS}

Doctors Trenor, Saiz and Giles shared responsibilities for study design. Computations were performed at Universidad Politécnica de Valencia by Doctors Cardona and Trenor, Dr. Giles wrote this manuscript. All authors contributed to final editing and the R-1 revisions.

\section{ACKNOWLEDGMENTS}

In Valencia, this work was supported by: (i) VI Plan Nacional de Investigación Científica, Desarrollo e Innovación Tecnológica from the Ministerio de Economía y Competitividad of Spain (TIN2012-37546-C03-01) and the European Commission (European Regional Development Funds-ERDF-FEDER), (ii) Plan Avanza en el marco de la Acción Estratégica de Telecomunicaciones y Sociedad de la Información del Ministerio de Industria Turismo y Comercio of Spain (TSI-020100-2010469), (iii) Programa deApoyo a la Investigación y Desarrollo (PAID-06-11-2002) de la Universitat Politècnica de València, (iv) Programa Prometeo (PROMETEO/2012/030) de la Consellería d'Educació Formació I Ocupació, Generalitat Valenciana, and (v) GileadSciences, Ltd. Wayne Giles acknowledges receipt of financial support in the form of a salary award (Medical Scientist) from Alberta Innovates-Health Solutions, and operating funding from the Canadian Institutes for Health Research and the Heart and Stroke Foundation of Alberta.

Belardinelli, L., Shryock, J. C., and Fraser, H. (2006). Inhibition of the late sodium current as a potential cardioprotective principle: effects of the late sodium current inhibitor ranolzaine. Heart 92(Suppl. 4), iv6iv14. doi: 10.1136/hrt.2005.078790

Bell, M. L., Peng, R. D., Dominici, F., and Samet, J. M. (2009). Emergency hospital admissions for cardiovascular diseases and ambient levels of carbon monoxide: results for 126 United States urban counties, 1999-2005. Circulation 120, 949-955. doi: 10.1161/ CIRCULATIONAHA.109.851113

Besse, I. A., Mitchell, C. C., Hund, T. J., and Shibata, E. F. (2011). A computational investigation of cardiac caveolae as a source of persistent sodium current. Front. Physiol. 2:87. doi: 10.3389/fphys.2011.00087 
Bouchard, R., Clark, R. B., Juhasz, A. E., and Giles, W. R. (2004). Changes in extracellular $\mathrm{K}^{+}$concentration modulate contractility of rat and rabbit cardiac myocytes via the inward rectifier $\mathrm{K}+$ current $\mathrm{I}_{K 1}$. J. Physiol. 556(pt 3), 773-790. doi: 10.1113/jphysiol.2003.058248

Campbell, D. L., Stamler, J. S., and Strauss, H. C. (1996). Redox modulation of L-type calcium channels in ferret ventricular myocytes. Dual mechanism regulation by nitric oxide and S-nitrosothiols. J. Gen. Physiol. 108, 277-293. doi: 10.1085/jgp.108.4.277

Clark, R. B., Bouchard, R. A., and Giles, W. R. (1996). Action potential duration modulates calcium influx, $\mathrm{Na}^{+}-\mathrm{Ca}^{2+}$ exchange, and intracellular calcium release in rat ventricular myocytes. Ann. N.Y. Acad. Sci. 779, 417-429. doi: 10.1111/j.17496632.1996.tb44817.x

Clusin, W. T. (2003). Calcium and cardiac arrhythmias: DADs, EADs, and alternans. Crit. Rev. Clin. Lab. Sci. 40, 337-375. doi: 10.1080/713609356

Corrias, A., Giles, W., and Rodiguez, B. (2011). Ionic mechnisms of elctrophysiological properties and repolarization abnormalities in rabbit Purkinje fibers. Am. J. Physiol. Heart Circ. Physiol. 300, H1806-H1813. doi: 10.1152/ajpheart.01170.2010

Cutler, M. J., Plummer, B. N., Wan, X., Sun, Q. A., Hess, D., Liu, H., et al. (2012). Aberrant S-nitrosylation mediates calcium-triggered ventricular arrhythmia in the intact heart. Proc. Natl. Acad. Sci. U.S.A. 109, 18186-18191. doi: 10.1073/pnas. 1210565109

Dallas, M. L., Yang, Z., Boyle, J. P., Boycott, H. E., Scragg, J. L., Milligan, C. J., et al. (2012). Carbon monoxide induces cardiac arrhythmia via induction of the late $\mathrm{Na}^{+}$current. Am. J. Respir. Crit. Care Med. 186, 648-656. doi: 10.1165/rccm.201204-0688OC.

Evans, J. R., and Bielefeldt, K. (2000). Regulation of sodium currents through oxidation and reduction of thiol residues. Neuroscience 101, 229-236. doi: 10.1016/S0306-4522(00)00367-5

Fink, M., Giles, W. R., and Noble, D. (2006). Contributions of inwardly rectifying $\mathrm{K}^{+}$currents to repolarization assessed using mathematical models of human ventricular myocytes. Philos. Trans. A Math. Phys. Eng. Sci. 364, 1207-1222. doi: 10.1098/rsta.2006.1765

Gaur, N., Rudy, Y., and Hool, L. (2009). Contributions of ion channel currents to ventricular action potential changes and induction of early afterdepolarizations during acute hypoxia. Circ. Res. 105, 1196-1203. doi: 10.1161/CIRCRESAHA.109.202267 Goldstein, M. (2008). Carbon monoxide poisoning. J. Emerg. Nurs. 34, 538-542. doi: 10.1016/j.jen.2007.11.014

Gómez, R., Caballero, R., Barana, A., Amorós, I., Calvo, E., López, J. A., et al. (2009). Nitric oxide increases cardiac $\mathrm{I}_{K 1}$ by nitrosylation of cysteine 76 of Kir2.1 channels. Circ. Res. 105, 383-392. doi: 10.1161/ CIRCRESAHA.109.197558

Gonzalez, D. R., Treuer, A. V., Castellanos, J., Dulce, R. A., and Hare, J. M. (2010). Impaired S-nitrosylation of the ryanodine receptor caused by xanthine oxidase activity contributes to calcium leak in heart failure. J. Biol. Chem. 285, 28938-28945. doi: 10.1074/jbc.M110.154948

Grandi, E., Pasqualini, F. S., and Bers, D. M. (2010). A novel computational model of the human ventricular action potential and $\mathrm{Ca}$ transient. J. Mol. Cell. Cardiol. 48, 112-121. doi: 10.1016/j.yjmcc.2009.09.019

Haas, J. S., and Landisman, C. E. (2011). State-dependent modulation of gap junction signaling by the persistent sodium current. Front. Cell. Neurosci. 5:31. doi: 10.3389/fncel.2011.00031

Haldar, S. M., and Stamler, J. S. (2013). S-nitrosylation: integrator of cardiovascular performance and oxygen delivery. J. Clin. Invest. 123, 101-110. doi: 10.1172/JCI62854

Houser, S. R. (2000). When does spontaneous sarcoplasmic reticulum $\mathrm{Ca}^{2+}$ release cause a triggered arrythmia? Cellular versus tissue requirements. Circ. Res. 87, 725-727. doi: 10.1161/01.RES.87. 9.725

Huelsing, D. J., Spitzer, K. W., and Pollard, A. E. (2000). Electrotonic suppression of early afterdepolarization in isolated rabbit Purkinje myocytes. Am. J. Physiol. Heart Circ. Physiol. 279, H250-H259.

Jaffrey, S. R., Erdjument-Bromage, H., Ferris, C. D., Tempst, P., and Snyder, S. H. (2001). Protein S-nitrosylation: a physiological signal for neuronal nitric oxide. Nat. Cell Biol. 3, 193-197. doi: 10.1038/35055104

Jaggar, J. H., Li, A., Parfenova, H., Liu, J., Umstot, E. S., Dopico, A. M., et al. (2005). Heme is a carbon monoxide receptor for large-conductance $\mathrm{Ca}^{2+}$-activated $\mathrm{K}^{+}$channels. Circ.
Res. 97, 805-812. doi: 10.1161/01. RES.0000186180.47148.7b

January, C. T., and Riddle, J. M. (1989). Early afterdepolarizations: mechanism of induction and block. A role for L-type $\mathrm{Ca}^{2+}$ current. Circ. Res. 64, 977-990. doi: 10.1161/01.RES.64.5.977

Ju, Y. K., Saint, D. A., and Gage, P. W. (1996). Hypoxia increases persistent sodium current in rat ventricular myocytes. J. Physiol. 497, 337-347.

Kawano, T., Zoga, V., Kimura, M., Liang, M. Y., Wu, H. E., Gemes, G., et al. (2009). Nitric oxide activates ATP-sensitive potassium channels in mammalian sensory neurons: action by direct S-nitrosylation. Mol. Pain 5, 12. doi: 10.1186/17448069-5-12

Kinobe, R. T., Dercho, R. A., and Nakatsu, K. (2008). Inhibitors of the heme oxygenase-carbon monoxide system: on the doorstep of the clinic? Can. J. Physiol. Pharmacol. 86, 577-599. doi: 10.1139/Y08-066

Leffler, C. W., Parfenova, H., Jaggar, J. H., and Wang, R. (2006). Carbon monoxide and hydrogen sulfide: gaseous messengers in cerebrovascular circulation. J. Appl. Physiol. 100, 1065-1076. doi: $10.1152 /$ japplphysiol.00793.2005

Liu, G. X., Choi, B. R., Ziv, O., Li, W., de Lange, E., Qu, Z., et al. (2012). Differential conditions for early after-depolarizations and triggered activity in cardiomyocytes derived from transgenic LQT1 and LQT2 rabbits. J. Physiol. 590, 1171-1180. doi: 10.1113/jphysiol. 2011.218164

Madhvani, R. V., Xie, Y., Pantazis, A., Garfinkel, A., Qu, Z., Weiss, J. N., et al. (2011). Shaping a new $\mathrm{Ca}^{2+}$ conductance to suppress early afterdepolarizations in cardiac myocytes. J. Physiol. 589, 6081-6092. doi: 10.1113/jphysiol.2011.219600

Maines, M. D. (1997). The heme oxygenase system: a regulator of second messenger gases. Annu. Rev. Pharmacol. Toxicol. 37, 517-554. doi: 10.1146/annurev.pharmtox.37. 1.517

Makielski, J. C., and Valdivia, C. R. (2006). Ranolazine and late cardiac sodium current-a therapeutic target for angina, arrhythmia and more? Br. J. Pharmacol. 148, 4-6. doi: $10.1038 /$ sj.bjp.0706713

Maleckar, M. M., Greenstein, J. L., Giles, W. R., and Trayanova, N. A. (2009). Electrotonic coupling between human atrial myocytes and fibroblasts alters myocyte excitability and repolarization. Biophys. J. 97, 2179-2190. doi: 10.1016/j.bpj.2009.07.054
Marban, E., Robinson, S. W., and Wier, W. G. (1986). Mechanisms of arrhythmogenic delayed and early afterdepolarizations in ferret ventricular muscle. J. Clin. Invest. 78, 1185-1192. doi: 10.1172/JCI112701

Moss, A. J., Zareba, W., Schwarz, K. Q., Rosero, S., McNitt, S., and Robinson, J. L. (2008). Ranolazine shortens repolarization in patients with sustained inward sodium current due to type-3 long-QT syndrome. J. Cardiovasc. Electrophysiol. 19, 1289-1293. doi: $10.1111 / j .1540$ 8167.2008.01246.x

Motterlini, R., and Otterbein, L. E. (2010). The therapeutic potential of carbon monoxide. Nat. Rev. Drug Discov. 9, 728-743. doi: 10.1038/nrd3228

Núñez, L., Vaquero, M., Gómez, R., Caballero, R., Mateos-Cáceres, P., Macaya, C., et al. (2006). Nitric oxide blocks hKv1.5 channels by S-nitrosylation and by a cyclic GMP-dependent mechanism. Cardiovasc. Res. 72, 80-89. doi: 10.1016/j.cardiores.2006.06.021

O'Hara, T., Virag, L., Varro, A., and Rudy, Y. (2011). Simulation of the undiseased human cardiac ventricular action potential: model formulation and experimental validation. PLoS Comput. Biol. 7:e1002061. doi: 10.1371/journal.pcbi.1002061

Saint, D. A. (2008). The cardiac persistent sodium current: an appealing therapeutic target? $\mathrm{Br}$. J. Pharmacol. 153, 1133-1142. doi: 10.1038/sj.bjp.0707492

Sarkar, A. X., Christini, D. J., and Sobie, E. A. (2012). Exploiting mathematical models to illuminate electrophysiological variability between individuals. J. Physiol. 590(pt 11), 2555-2567. doi: 10.1113/jphysiol.2011.223313

Sarkar, A. X., and Sobie, E. A. (2011). Quantification of repolarization reserve to understand interpatient variability in the response to proarrhythmic drugs: a computational analysis. Heart Rhythm 8, 1749-1755. doi: 10.1016/j.hrthm.2011.05.023

Shampine, L. F., and Reichelt, M. W. (1997). The MATLAB ODE suite. SIAM J. Sci. Comput. 18, 1-22. doi: 10.1137/S1064827594276424

Spitzer, K. W., Pollard, A. E., Yang, L., Zaniboni, M., Cordeiro, J. M., and Huelsing, D. J. (2006). Cell-to-cell electrical interactions during early and late repolarization. J. Cardiovasc. Electrophysiol. 17(Suppl. 1), S8-S14. doi: 10.1111/j.1540-8167.2006.00379.x

Tamargo, J., Caballero, R., Gómez, R., and Delpón, E. (2010). Cardiac 
electrophysiological effects of nitric oxide. Cardiovasc. Res. 87, 593-600. doi: $10.1093 / \mathrm{cvr} / \mathrm{cvq} 214$

Tao, T., Paterson, D. J., and Smith, J. P. (2011). A model of cellular cardiac-neutral coupling that captures the sympathetic control of sinoatrial node excitability in normotensive and hypertensive rats. Biophys. J. 101, 594-602. doi: 10.1016/j.bpj.2011.05.069

Terkildsen, J. R., Niederer, S., Crampin, E. J., Hunter, P., and Smith, N. P. (2008). Using Physiome standards to couple cellular functions for rat cardiac excitation-contraction. Exp. Physiol. 93, 919-929. doi: 10.1113/expphysiol.2007.041871

Thomas, G., Killeen, M. J., Grace, A. A., and Huang, C. L. (2008). Pharmacological separation of early afterdepolarizations from arrhythmogenic substrate in DeltaKPQ Scn5a murine hearts modelling human long QT 3 syndrome. Acta Physiol. 192, 505-517. doi: 10.1111/j.1748-1716.2007.01770.x

Trenor, B., Cardona, K., Gomez, J. F., Rajamani, S., Ferrero, J. M., Belardinelli, L., et al. (2012). Simulation and mechanistic investigation of the arrhythmogenic role of the late sodium current in human heart failure. PLoS ONE 7:e32659. doi: 10.1371/journal.pone.0032659

Trenor, B., Gomis-Tena, J., Cardona, K., Romero, L., Rajamani, S., Belardinelli, L., et al. (2013). In silico assessment of drug safety in human heart applied to late sodium current blockers. Channels (Austin) 7, 1-14. doi: 10.4161/chan.24905

Ueda, K., Valdivia, C., MedeirosDomingo, A., Tester, D. J., Vatta, M., Farrugia, G., et al. (2008). Syntrophin mutation associated with long QT syndrome through activation of the nNOS-SCN5A macromolecular complex. Proc. Natl. Acad. Sci. U.S.A. 105, 9355-9360. doi: 10.1073/pnas.0801294105

Varró, A., and Baczkó, I. (2011). Cardiac ventricular repolarization reserve: a principle for understanding drug-related proarrhythmic risk. $\mathrm{Br} . \mathrm{J}$. Pharmacol. 164, 14-36. doi: 10.1111/j.1476-5381.2011.01367.x

Wang, H., Viatchenko-Karpinski, S., Sun, J., Györke, I., Benkusky, N. A., Kohr, M. J., et al. (2010). Regulation of myocyte contraction via neuronal nitric oxide synthase: role of ryanodine receptor S-nitrosylation. J. Physiol. 588(pt 15), 2905-2917. doi: 10.1113/jphysiol. 2010.192617

Wilkinson, W. J., and Kemp, P. J. (2011). Carbon monoxide: an emerging regulator of ion channels. J. Physiol. 589, 3055-3062. doi: 10.1113/jphysiol.2011.206706

Winslow, R. L., Cortassa, S., O'Rourke, B., Hashambhoy, Y. L., Rice, J. J., and Greenstein, J. L. (2011). Integrative modeling of the cardiac ventricular myocyte. Wiley Interdiscip. Rev. Syst. Biol. Med. 3, 392-413. doi: 10.1002/wsbm. 122

Wu, L., Rajamani, S., Li, H., January, C. T., Shryock, J. C., and Belardinelli, L. (2009). Reduction of repolarization reserve unmasks the proarrhythmic role of endogenous late $\mathrm{Na}^{+}$current in the heart. Am. J. Physiol. Heart Circ. Physiol. 297, H1048-H1057. doi: 10.1152/ajpheart.00467.2009

Wu, L., and Wang, R. (2005). Carbon monoxide: endogenous production, physiological functions, and pharmacological applications. Pharmacol. Rev. 57, 585-630. doi: 10.1124/pr.57.4.3

Yakushev, S., Band, M., Tissot van Patot, M. C., Gassmann, M., Avivi, A., and Bogdanova, A. (2012). Cross talk between S-nitrosylation and Sglutathionylation in control of the $\mathrm{Na}, \mathrm{K}-\mathrm{ATPa} e$ regulation in hypoxic heart. Am. J. Physiol. Heart Circ. Physiol. 303, H1332-H1343. doi: 10.1152/ajpheart.00145.2012

Zaniboni, M., Pollard, A. E., Yang, L., and Spitzer, K. W. (2000). Beatto-beat repolarization variability in ventricular myocytes and its supppression by electrical coupling. Am. J. Physiol. Heart Circ. Physiol. 278, SH677-SH687.

Zaza, A., Belardinelli, L., and Shryock, J. C. (2008). Pathophysiology and pharmacology of the cardiac "late sodium current."
Pharmacol. Ther. 119, 326-339. doi: 10.1016/j.pharmthera.2008.06.001

Conflict of Interest Statement: The authors declare that the research was conducted in the absence of any commercial or financial relationships that could be construed as a potential conflict of interest.

Received: 30 July 2013; paper pending published: 14 August 2013; accepted: 18 September 2013; published online: 17 October 2013.

Citation: Trenor B, Cardona K, Saiz J, Rajamani S, Belardinelli $L$ and Giles WR (2013) Carbon monoxide effects on human ventricle action potential assessed by mathematical simulations. Front. Physiol. 4:282. doi: 10.3389/fphys. 2013.00282

This article was submitted to Cardiac Electrophysiology, a section of the journal Frontiers in Physiology.

Copyright (c) 2013 Trenor, Cardona, Saiz, Rajamani, Belardinelli and Giles. This is an open-access article distributed under the terms of the Creative Commons Attribution License (CC BY). The use, distribution or reproduction in other forums is permitted, provided the original author(s) or licensor are credited and that the original publication in this journal is cited, in accordance with accepted academic practice. No use, distribution or reproduction is permitted which does not comply with these terms. 